\title{
Application of Industrial Wastes from Chemically Treated Aluminum Saline Slags as Adsorbents
}

\author{
Antonio Gil, ${ }^{*}{ }^{\dagger \oplus}$ Ekhine Arrieta, ${ }^{\dagger}$ Miguel Ángel Vicente, ${ }^{\ddagger \oplus}$ and Sophia A. Korili ${ }^{\dagger}$ \\ ${ }^{\dagger}$ INAMAT-Departamento de Ciencias, Edificio de los Acebos, Universidad Pública de Navarra, Campus de Arrosadía, E-31006 \\ Pamplona, Spain \\ ${ }^{\ddagger}$ GIR-QUESCAT, Departamento de Química Inorgánica, Universidad de Salamanca, E-37008 Salamanca, Spain
}

Supporting Information

\begin{abstract}
In this study, industrial wastes, which remain after aluminum extraction from saline slags, were used as adsorbents. The aluminum saline slags were treated under reflux with $2 \mathrm{~mol} /$ $\mathrm{dm}^{3}$ aqueous solutions of $\mathrm{NaOH}, \mathrm{H}_{2} \mathrm{SO}_{4}$, and $\mathrm{HCl}$ for $2 \mathrm{~h}$. After separation by filtration, aqueous solutions containing the extracted aluminum and residual wastes were obtained. The wastes were characterized by nitrogen adsorption at $-196{ }^{\circ} \mathrm{C}$, X-ray diffraction, scanning electron microscopy, and ammonia pulse chemisorption. The chemical treatment reduced the specific surface area, from 84 to $23 \mathrm{~m}^{2} / \mathrm{g}$, and the pore volume, from 0.136 to $0.052 \mathrm{~cm}^{3} / \mathrm{g}$, of the saline slag and increased the ammonia-adsorption capacity from 2.84 to $5.22 \mathrm{~cm}^{3} / \mathrm{g}$, in the case of acid-treated solids. The materials were applied for the removal of Acid Orange 7 and Acid Blue 80
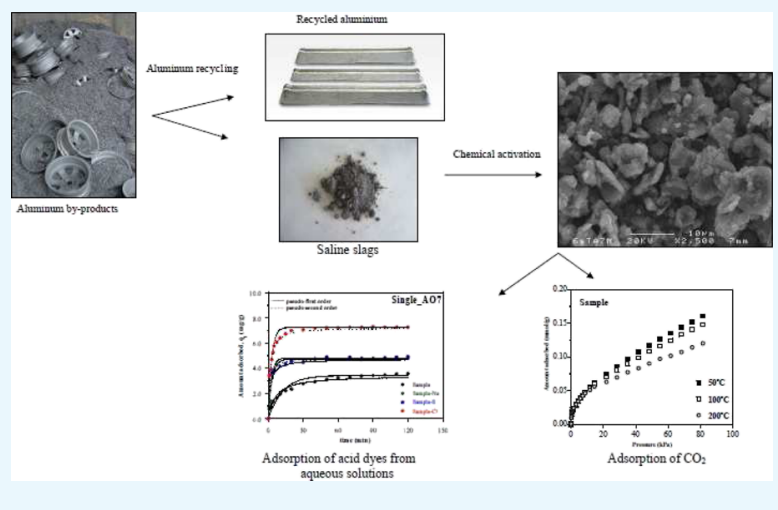
from aqueous solutions, considering both single and binary systems. The results showed interesting differences in the adsorption capacity between the samples. The saline slag treated with $\mathrm{HCl}$ rapidly adsorbed all of the dyes present in solution, whereas the other materials retained between 50 and $70 \%$ of the molecules present in solution. The amount of Acid Orange 7 removed by the nontreated material and by the material treated with $\mathrm{NaOH}$ increased in the presence of Acid Blue 80, which can be considered as a synergistic behavior. The $\mathrm{CO}_{2}$ adsorption of the solids at several temperatures up to $200{ }^{\circ} \mathrm{C}$ was also evaluated under dry conditions. The aluminum saline slag presented an adsorption capacity higher than the rest of treated samples, a behavior that can be explained by the specific sites of adsorption and the textural properties of the solids. The isosteric heats of $\mathrm{CO}_{2}$ adsorption, determined from the Clausius-Clapeyron equation, varied between 1.7 and $26.8 \mathrm{~kJ} / \mathrm{mol}$. The wastes should be used as adsorbents for the selective removal of organic contaminants in wastewater treatment.
\end{abstract}

\section{INTRODUCTION}

Related to their complex aromatic structures, dyes present in industrial effluents create bad taste, odors, and unsightly color and can even have carcinogenic effects even at low concentrations. Acid dyes are more problematic than basic ones because anions are very weakly retained by most soil components and hence cause contamination of surface waters. ${ }^{1}$ Adsorption technologies have been proven to be effective and cost-efficient for treating wastewaters with the presence of organic contaminants because of their design simplicity, insensitivity to toxic substances, and high efficiency. ${ }^{2,3}$ Several adsorbents, including activated carbons and zeolites, among others, are commonly used for this purpose. In addition, development of low-cost adsorbents from industrial wastes has a growing interest; among them, activated saline slags generated during secondary aluminum melting processes are considered to be interesting materials for being used in this field, as previously reported by our research groups. ${ }^{4}$

Multiple organic contaminants are usually found in wastewater systems, suggesting possible interactions between these organic molecules. The competitive effects between these coexisting simultaneous contaminants on removal must therefore be considered to study how these molecules can be removed from wastewater. Although several studies have reported adsorption processes for single-component systems, ${ }^{3}$ limited studies have considered the adsorption of organic molecules in multiple systems. ${ }^{5-25}$ For example, the adsorption of three acid dyes, namely Acid Blue 80, Acid Red 114, and Acid Yellow 117, on an activated carbon showed that the molecular size and chemical groups can contribute to the relative differences found for the adsorption capacities of these three dyes. ${ }^{6}$ Similarly, the activated carbon produced from the phosphoric acid treatment of waste bamboo scaffolding and activated at several temperatures was evaluated as an adsorbent for two acid dyes by Chan et al., ${ }^{15}$ who reported an effect of the porosity of the activated carbons and the molecular size of

Received: September 15, 2018

Accepted: December 12, 2018

Published: December 26, 2018 
the dyes on the adsorption capacity. In a related study, the simultaneous removal of two industrial dyes by adsorption and photocatalysis on a fly ash $\mathrm{TiO}_{2}$ composite was studied by Duta and Visa, ${ }^{20}$ and they found that the efficiency of adsorption strongly depended on the microporous structure of the adsorbent and that the kinetics depended on the flexibility of the dyes. A mixed biosorbent containing carboxyl and amine groups was prepared by $\mathrm{Yu}$ et al. ${ }^{21}$ to treat an aqueous solution containing cationic and anionic dyes, namely Basic Red 9 and Direct Red 28, whereas Yang et al. ${ }^{23}$ reported $\mathrm{MnFe}_{2} \mathrm{O}_{4}$ as an adsorbent for the removal of Basic Blue 9 and Direct Red 28 in single and binary systems. Considering single solutions, the adsorption rate for Basic Blue 9 was generally higher than that for Direct Red 28, and the adsorption equilibrium time for Basic Blue 9 was shorter than that for Direct Red 28. The interaction between the dyes showed a synergistic effect, where the adsorption of Direct Red 28 on the adsorbent was promoted. The surface and porosity properties of the adsorbents and the characteristics of the adsorbates are, in general, the factors that most affect the adsorption process.

$\mathrm{CO}_{2}$ emissions to the atmosphere must be controlled to reduce the $\mathrm{CO}_{2}$ levels that affect global warming. Adsorbents such as zeolites, carbon-derived materials, hydrotalcites, aminefunctionalized mesoporous silicas, and metal organic frameworks have been considered as potential solids to capture $\mathrm{CO}_{2}{ }^{26-30}$ The $\mathrm{CO}_{2}$ uptake capacities under several conditions of temperature and pressure, the stability in the presence of water, and the conditions for the regeneration of the materials have been evaluated as important aspects to select the suitable adsorbents. The development of effective low-cost and renewable $\mathrm{CO}_{2}$ adsorbents is also mandatory. With these ideas, $\mathrm{CO}_{2}$ adsorbents from waste precursors have been reported, including byproducts derived from coal, biomass, water treatment, eggshells and mussel shells, lime mud, and fly ash, among others. ${ }^{31-34}$

In the present study, industrial wastes resulting from the extraction of aluminum from saline slag wastes were selected as porous adsorbents for the uptake of Acid Blue 80 and Acid Orange 7 from aqueous solutions, including both single and binary systems, and of $\mathrm{CO}_{2}$ in the temperature interval from 50 to $200{ }^{\circ} \mathrm{C}$ and pressures up to $80 \mathrm{kPa}$. As a first objective, the study included the assessing of the competitive behavior of Acid Orange 7 and Acid Blue 80 in single and binary solutions. As a second objective, the study considered the capacity of $\mathrm{CO}_{2}$ adsorption of the adsorbents at three temperatures and up to a pressure of $80 \mathrm{kPa}$ and the estimation of the isosteric heat of adsorption using the Clausius-Clapeyron equation.

\section{RESULTS AND DISCUSSION}

2.1. Characterization of the Adsorbents. Acid and alkaline material treatments have been widely studied for the elimination of mineral impurities, disaggregation of particles, and dissolution of elements such as $\mathrm{Mg}^{2+}$ or $\mathrm{Al}^{3+}$. Depending on the intensity and the type of material, the treatment could produce modification of the textural properties and the number of acid centers. ${ }^{4}$ When $\mathrm{H}_{3} \mathrm{PO}_{4}$ or $\mathrm{H}_{2} \mathrm{SO}_{4}$ is used in the treatment, the incorporation of $\mathrm{PO}_{4}{ }^{3-}$ or $\mathrm{SO}_{4}{ }^{2-}$ onto the surface of the materials can take place, which may affect their interaction with adsorbate molecules.

The $\mathrm{N}_{2}$ adsorption-desorption results for samples at -196 ${ }^{\circ} \mathrm{C}$ are summarized in Figure 1. The adsorption isotherms are of type II in the BDDT classification, ${ }^{35}$ with an H3-type hysteresis loop. ${ }^{36}$ The hysteresis loop is related to materials

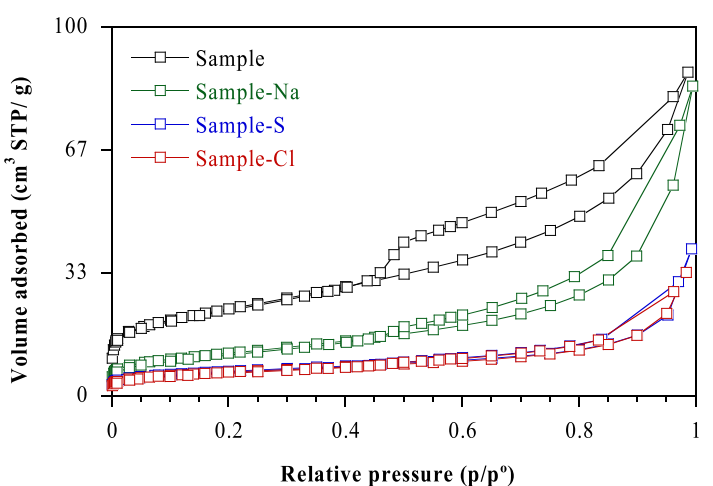

Figure 1. Experimental isotherms for the adsorption of nitrogen at $-196{ }^{\circ} \mathrm{C}$.

comprising aggregates of platelike particles forming slitlike pores. The nitrogen adsorption capacity decreases with the chemical treatment. In the case of sample-S and sample-Cl, both samples show almost the same capacity. The results related to the textural properties of the reference sample and the activated samples are listed in greater detail in Table 1. Treatment under reflux conditions with water did not have a marked effect on the textural properties of the reference sample. In contrast, the specific surface area and pore volume of the sample decreased when treated with acids or bases. The specific surface area decreases between 50 and $73 \%$ and the total volume of pores decreases between 4 and $62 \%$. Average pore sizes increase with treatment, from 15.7 to $24.6 \mathrm{~nm}$. These findings suggest that a porous solid is dissolved during the treatments, mainly under acid conditions. These results are in accordance with those obtained previously, where the effect of time and concentration of various chemical reagents was studied. $^{4}$

The powder X-ray diffraction (XRD) pattern for sample- $\mathrm{Na}$ is very similar to that of sample (Figure 2), in agreement with the fact that the raw sample was previously treated with water at high temperature to remove the soluble salts usually present in this type of waste, and this washing was actually carried out under alkaline conditions as a consequence of the presence of nitrides in the raw sample. ${ }^{37}$ In the case of the samples treated with acids, some diffraction peaks for the original sample, such as those for calcite, disappear, whereas others, such as those for calcium and magnesium sulfate, appear after the sample is treated with $\mathrm{H}_{2} \mathrm{SO}_{4}$. This suggests that $\mathrm{Ca}^{2+}$ is dissolved from the slag by the acid treatment, that is, from calcite and calcium aluminate, but it then precipitates as sulfate because of the insolubility of this salt. The chemical composition of this type of waste is very complex and depends on the raw material used. The main crystalline phases detected by various authors include aluminum oxide (various phases), metallic $\mathrm{Al}$, magnesium aluminate, magnesium oxide, and calcium aluminate. ${ }^{38-40}$ The main peaks from these phases are marked in Figure 2, confirming their presence in our slag. The presence of other compounds (or elements) was not detected although it cannot be ruled out; they may be in the form of amorphous phases or also as crystalline phases but in very low amounts, in both cases not detected by XRD.

The morphology changes caused by the chemical treatments are compared from the scanning electron microscopy (SEM) images for the four samples (Figure 3). No significant differences can be observed between sample (A) and sample$\mathrm{Na}$ (B). The particles from sample-S (C) had a small size and 
Table 1. Specific Surface Areas, Pore Volumes, Pore Diameters, pzc, and Acidity Properties of the Samples

$\begin{array}{lccccccc} & S_{\mathrm{BET}}{ }^{a}\left(\mathrm{~m}^{2} / \mathrm{g}\right) & S_{\text {ext }}^{b}\left(\mathrm{~m}^{2} / \mathrm{g}\right) & V_{\mathrm{pT}^{c}}\left(\mathrm{~cm}^{3} / \mathrm{g}\right) & V_{\mu \mathrm{p}}^{b}\left(\mathrm{~cm}^{3} / \mathrm{g}\right) & d_{\mathrm{pBJH}}(\mathrm{nm}) & \mathrm{pHpzc} & V\left(\mathrm{NH}_{3}\right)\left(\mathrm{cm}^{3} / \mathrm{g}\right) \\ \text { sample } & 84 & 64 & 0.136 & 0.010 & 15.7 & 8.6 & 2.84 \\ \text { sample-Na } & 42 & 38 & 0.130 & 0.002 & 24.2 & 9.7 & 3.35 \\ \text { sample-S } & 24 & 14 & 0.062 & 0.005 & 24.6 & 2.0 & 5.21 \\ \text { sample-Cl } & 23 & 13 & 0.052 & 0.005 & 24.3 & 3.7 & 5.22\end{array}$

${ }^{a}$ Brunauer-Emmett-Teller (BET) specific surface area calculated in the relative pressure range of $0.05-0.20 .{ }^{b}$ External surface area and micropore volume estimated from the $t$-plot method. ${ }^{c}$ Total pore volume calculated at a relative pressure of 0.99 .

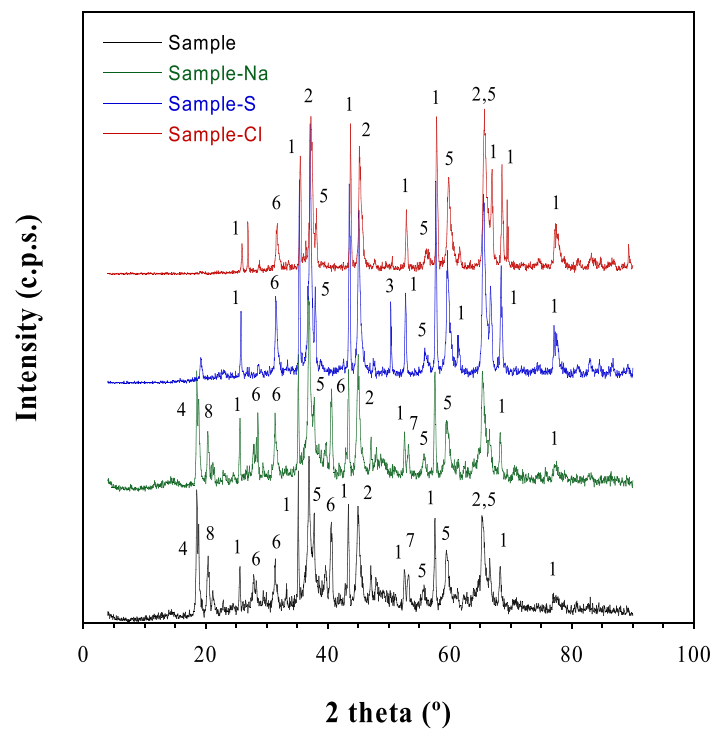

Figure 2. XRD patterns for the samples. [(1) $\left.\mathrm{Al}_{2} \mathrm{O}_{3}, \mathrm{ICDD} 46-1212\right]$, [(2) metallic Al], [(3,8) $\mathrm{CaSO}_{4}$, ICDD 36-0432], [(4) calcite, ICDD 05-0586], [(5) $\mathrm{MgAl}_{2} \mathrm{O}_{4}$, ICDD 21-1152], [(6) calcium aluminate, ICDD 70-0134], and [(7) MgO, ICDD 45-946].

had the tendency to form aggregates. This characteristic was not showed for the sample treated with $\mathrm{HCl}$, sample-Cl (D). The qualitative composition of the samples is also characterized by energy-dispersive X-ray (EDX) analysis. Several metals and metal oxides are detected indicating the complexity of the samples as an industrial waste. The presence of $S$ in sample-S is also confirmed.

Ammonia chemisorption provides a measure of the concentration of acid sites. The total acidity results, as $\mathrm{cm}_{\mathrm{NH}_{3}}{ }^{3} / \mathrm{g}$, are given in Table 1 . The acidity of the samples increases from 2.84 to $5.22 \mathrm{~cm}^{3} \mathrm{NH}_{3} / \mathrm{g}$ after the activation treatment, mainly in the case of samples treated with acids.

2.2. Dye Adsorption Experiments. The contact time is a parameter that is known to control adsorption processes to determine the equilibrium time.

The $\mathrm{pH}$ conditions strongly influence the adsorption processes, as they condition the charge of the dye molecules, the charge of the solid surface, and so forth. Thus, to evaluate the effect of solution $\mathrm{pH}, 0.2 \mathrm{~g}$ of the sample was added to 100 $\mathrm{cm}^{3}$ of aqueous solutions containing $15 \mathrm{mg} / \mathrm{dm}^{3}$ of $\mathrm{AB} 80$ or $\mathrm{AO} 7\left(0.022\right.$ and $0.042 \mathrm{mmol} / \mathrm{dm}^{3}$, respectively) at various $\mathrm{pH}$ values in the range of $2-9$. The resulting suspensions were shaken for $120 \mathrm{~min}$. The maximum percentage of dye removal was observed at $\mathrm{pH} 2$, which is explained by the electrostatic interactions between the adsorbate and the surface of the adsorbents. One of the main parameters reported to govern adsorption is the point of zero charge (pzc) of the surface of the solids. By this reason, the pHpzc of solids, sample, sample-
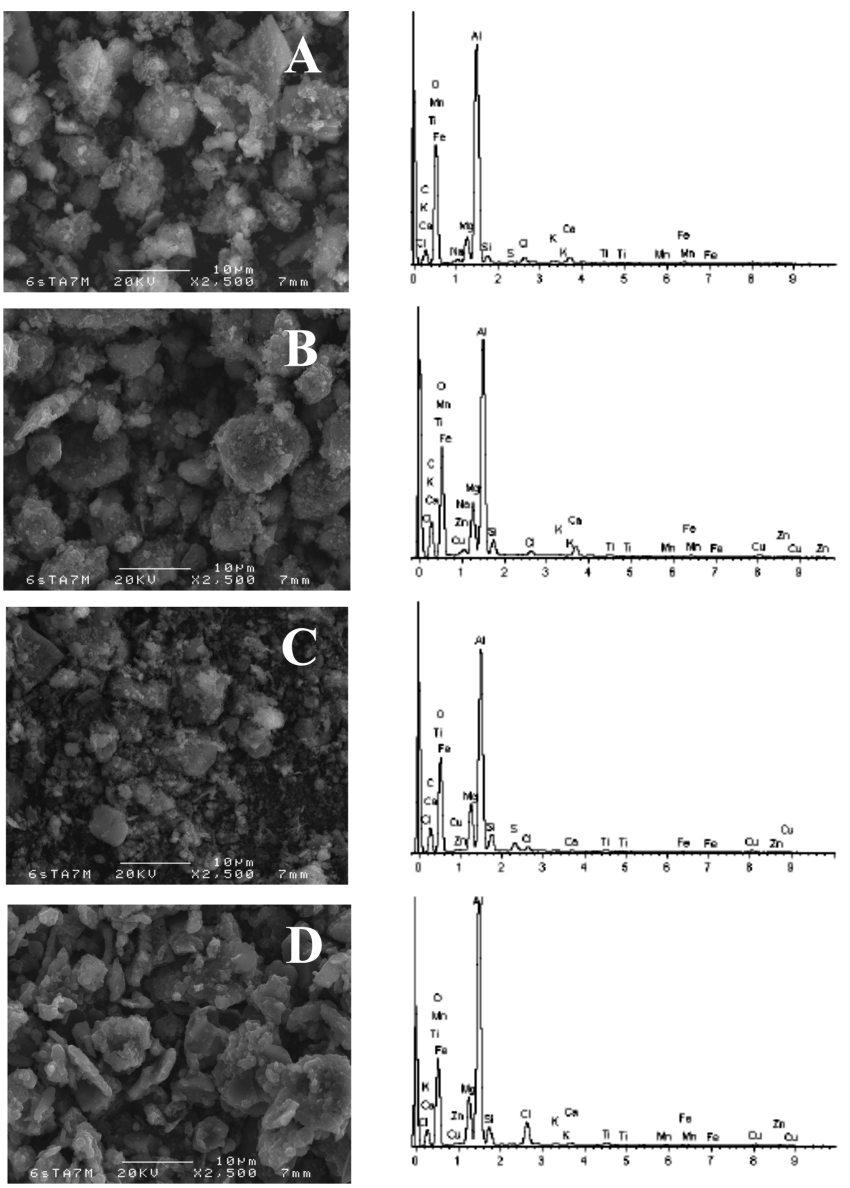

Energy (keV)

Figure 3. SEM images and EDX analysis for the samples. (A) Sample, (B) sample-Na, (C) sample-S, and (D) sample-Cl.

$\mathrm{Na}$, sample-Cl, and sample-S, was determined according to the method previously reported ${ }^{41}$ and found to be 8.6, 9.7, 3.7, and 2.0 , respectively (see Table 1 ). Under the $\mathrm{pH}$ conditions for adsorption, all samples show a positively charged surface; therefore adsorption is improved at acidic $\mathrm{pH}$. In the case of the dye molecules, the values of $\mathrm{pK}_{\mathrm{a}}$ must be taken into account (see Table S1, Supporting Information). Similar trends have been reported by other authors, such as Kyzas et al., ${ }^{42}$ who described the adsorption of Acid Orange 7 and Acid Green 25 on the surface of cerium oxide. Also considering that a lot of industrial wastewater is strongly acidic, a $\mathrm{pH}$ value of 2 was selected for the additional experiments.

The evolution of the amounts of dye adsorbed with time for the single solutions is shown in Figure 4. Dye removal was rapid in the initial stages, reaching equilibrium after around 40 min. Moreover, AB80 adsorbs more rapidly than AO7. The factors affecting the adsorption selectivity of an adsorbent for 

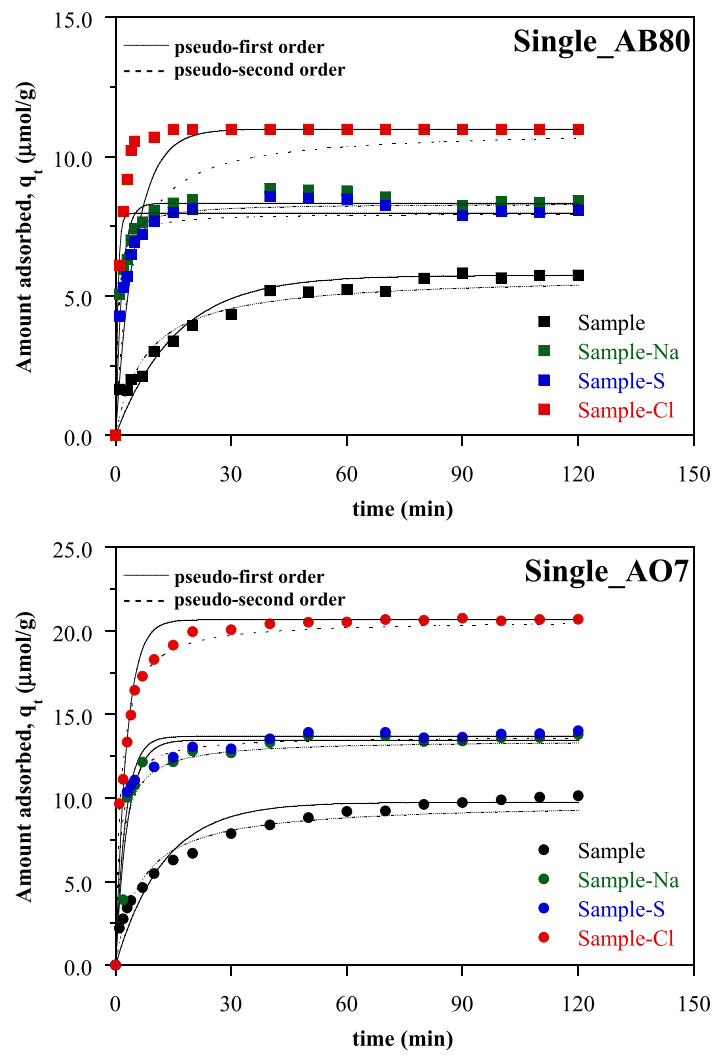

Figure 4. Kinetic adsorption data of $A B 80$ and $A O 7$ using samples as adsorbents. $T=25^{\circ} \mathrm{C}, C_{0}=15 \mathrm{mg} / \mathrm{dm}^{3}\left(0.022 \mathrm{mmol} / \mathrm{dm}^{3}\right.$ for $\mathrm{AB} 80$ and $0.022 \mathrm{mmol} / \mathrm{dm}^{3}$ for $\left.\mathrm{AO} 7\right)$, and $\mathrm{pH}=2$. The lines represent a pseudo-first-order model (-) and a pseudo-second-order model (---).

several kinds of adsorbates may be related to the characteristics of the active sites (functional groups, porous structure, surface properties, etc.), the characteristics of the adsorbates (molecular structure, ionic nature, etc.), and the solution chemistry (ionic strength, pH, etc.). ${ }^{4,6,10,11,13}$ The adsorption of acidic dyes is mostly governed by physical adsorption; therefore, the structure of these dyes could be the principal factor that affects the adsorption capacity. ${ }^{8}$ The acidic dyes used in this study contain two (AB80) and one sulfonic acid groups (AO7) (see Table S1, Supporting Information), and therefore these differences could explain their adsorption behavior when only one adsorbate is considered. Several authors have explained the results found for other dyes on the basis of the structures of the molecules and the porosity properties of the adsorbents, mainly activated carbons, which have high specific surface areas. ${ }^{15,20,42,43}$ In the case of industrial wastes, which do not tend to be carbon-based, the chemical surface properties should be taken into consideration when explaining the removal of dyes from aqueous solutions. In general, the adsorption capacity of the waste increased after chemical treatment with $\mathrm{HCl}, \mathrm{H}_{2} \mathrm{SO}_{4}$, and $\mathrm{NaOH}$ (see the results summarized in Figure 4). Thus, the adsorption capacity of the activated wastes increased from $9.7 \mu \mathrm{mol} / \mathrm{g}$ for $\mathrm{AO} 7$ and the nonactivated waste (sample) to $20.7 \mu \mathrm{mol} / \mathrm{g}$ for the activated waste treated with $\mathrm{HCl}$ (sample-Cl). The wastes treated with $\mathrm{NaOH}$ and $\mathrm{H}_{2} \mathrm{SO}_{4}$ showed the same adsorption capacity, $13.6 \mu \mathrm{mol} / \mathrm{g}$. In the case of $\mathrm{AB} 80$, the adsorption capacities obtained were 5.7 (sample), 8.0 (sample-S), 8.3 (sample-Na), and $11.0 \mu \mathrm{mol} / \mathrm{g}$ (sample-Cl). The efficiency of adsorption was also determined by taking into account the amounts of dyes adsorbed and the initial amounts brought into contact with the adsorbents. In general, the adsorbents removed more $\mathrm{AB} 80$ than $\mathrm{AO} 7$, probably because of the sulfonic acid groups on the molecules. Thus, sample- $\mathrm{Cl}$ adsorbed $100 \%$ of the dyes present in solution, without differentiating between one dye and the other, whereas sample$S$ and sample- $\mathrm{Na}$ adsorbed between 73 and $79 \%$ of $\mathrm{AB} 80$ and $66 \%$ of $\mathrm{AO} 7$. The nonactivated waste adsorbed $47 \%$ of $\mathrm{AO} 7$ and $52 \%$ of $A B 80$. These experimental results indicate that the acid sites on the surface of the adsorbents appear to favor the interaction with acid dyes. In this context and also considering the phases identified by XRD (see Figure 2), alumina and calcium aluminate are the two phases that may be more easily protonated at low $\mathrm{pH}$. Although the presence of sulfate on the surface (see Figure 3, EDX analysis) increases the acidity of the solid, it also reduces the adsorption capacity of the material by interaction/repulsion with the dye molecules. The adsorption capacity remains at the same level for the sample activated with $\mathrm{NaOH}$. The maximum amount of dye adsorbed at equilibrium was reached after $120 \mathrm{~min}$ for all samples.

The reusability of the materials was estimated from the solids separated from the liquid by centrifugation. The samples were treated with $0.1 \mathrm{~mol} / \mathrm{dm}^{3}$ of $\mathrm{NaCl}$ for $1 \mathrm{~h}$ to desorb the organic molecules. The saline solution was filtered from the solid by a new cycle of centrifugation, and the solid was washed several times with deionized water before being reused as the adsorbent. The process was duplicated, and the amount of $\mathrm{AB} 80$ and $\mathrm{AO} 7$ adsorbed for each reuse stage is given in Figure 5.

The comparative evolution of the amounts of dyes adsorbed with time for the single and binary solutions is shown in Figure 6. When the adsorption of the dyes occurs individually, $\mathrm{AO} 7$ is adsorbed to a greater extent compared to AB80. A comparison of the results obtained when the binary system is used shows clear differences between the adsorbents. Thus, sample and sample-Na adsorb high quantities of $\mathrm{AO} 7$, even higher than the amounts of this dye adsorbed in the single systems. This result suggests that the adsorption of $\mathrm{AO} 7$ is affected by the presence of AB80 during the competitive process. The increase in the adsorption of $\mathrm{AO} 7$ suggests that synergistic $\mathrm{AB} 80$ adsorption forces $\mathrm{AO} 7$ to be retained at sorption sites with greater affinity. Sample- $\mathrm{Cl}$ adsorbs the same amount of dyes in the binary solution as when the dyes are in single solutions. Sample-S adsorbs lower amount for both dye molecules. Thus, when the two molecules are adsorbed individually, the materials do not selectively adsorb either of them, only with differences in the adsorption rate at the initial stages. When both molecules are present in the same solution, sample and sample-Na selectively adsorb AO7, which may allow this molecule to be separated from AB80. Acid-activated solids exhibit practically no differences in adsorption when both molecules are present in solution, mainly in the case of sample- $\mathrm{Cl}$.

Equations 6 and 7 were used to predict the mechanism involved in the adsorption process of dyes on activated samples, with the adsorption kinetic parameters being estimated by nonlinear regression (see Figure 4 and Tables S2 and S3, Supporting Information). By analyzing the coefficient of determination $(R)$ and the chi-square test $\left(\chi^{2}\right)$ values of the kinetic models, the pseudo-second-order kinetic model was the best in describing the adsorption kinetics of dyes in single and binary component systems. As described in the Theoretical Approach section, such kinetic models are better considered as simple empirical equations useful for predicting the kinetics of 

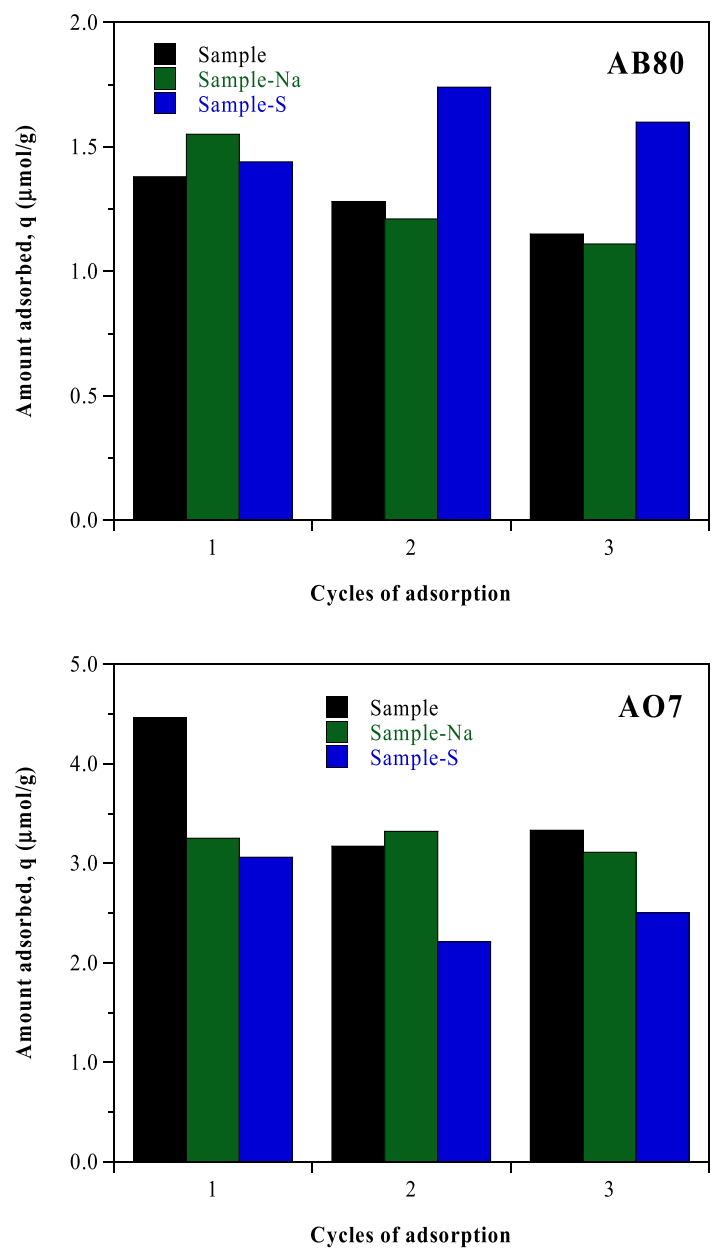

Figure 5. Reusability of the samples for $\mathrm{AB} 80$ and $\mathrm{AO} 7$ adsorption. adsorption systems and for designing adsorption units but do not reflect the chemical and physical phenomena occurring. Additionally, as the concentrations of dyes used for this type of tests are small, adsorption in monolayer or adsorption in specific adsorption sites will be favored, which could be considered as chemisorption. In the same way, the values and trends of the constants of these models $\left(k_{1}\right.$ and $\left.k_{2}\right)$ do not allow to reach any conclusion.

To better understand the adsorption mechanism of $\mathrm{AO} 7$ and $\mathrm{AB} 80$ on activated samples, the intraparticle diffusion model was considered. The $q_{t}$ versus $t^{0.5}$ plots for the adsorption of dyes are given in Figure S1, whereas Tables S2 and S3 list the related parameters. The first linear portions represent the external mass transfer and the binding of the dye by the active sites distributed on the surface of activated samples. The second linear portions, which determine the adsorption rate, describe intraparticle diffusion and binding of dyes by active sites inside the pores of activated samples. As can be deduced from the data in Tables S2 and S3, the $k_{3}$ values increase with chemical activation, indicating fast adsorption of the dyes on the surface of the solids. Table 2 summarizes the effective diffusion coefficients. The low values of $D / r^{2}$ can be related to the limited participation of intraparticle diffusion in dye adsorption on the saline slags, also related to the low textural properties of the materials. The activation of the materials increases the diffusion coefficients, being higher for $\mathrm{AB} 80$ than for $\mathrm{AO} 7$, probably due to the sulphonic acid groups of the dye molecules (see Table S1, Supporting Information).

The equilibrium adsorption isotherm was considered important to describe the interactive behavior between adsorbates and adsorbents. Langmuir isotherm equation was thus used for modeling the experimental data. The parameters for the isotherm equation, estimated by nonlinear regression, are summarized in Table S4 (Supporting Information). The
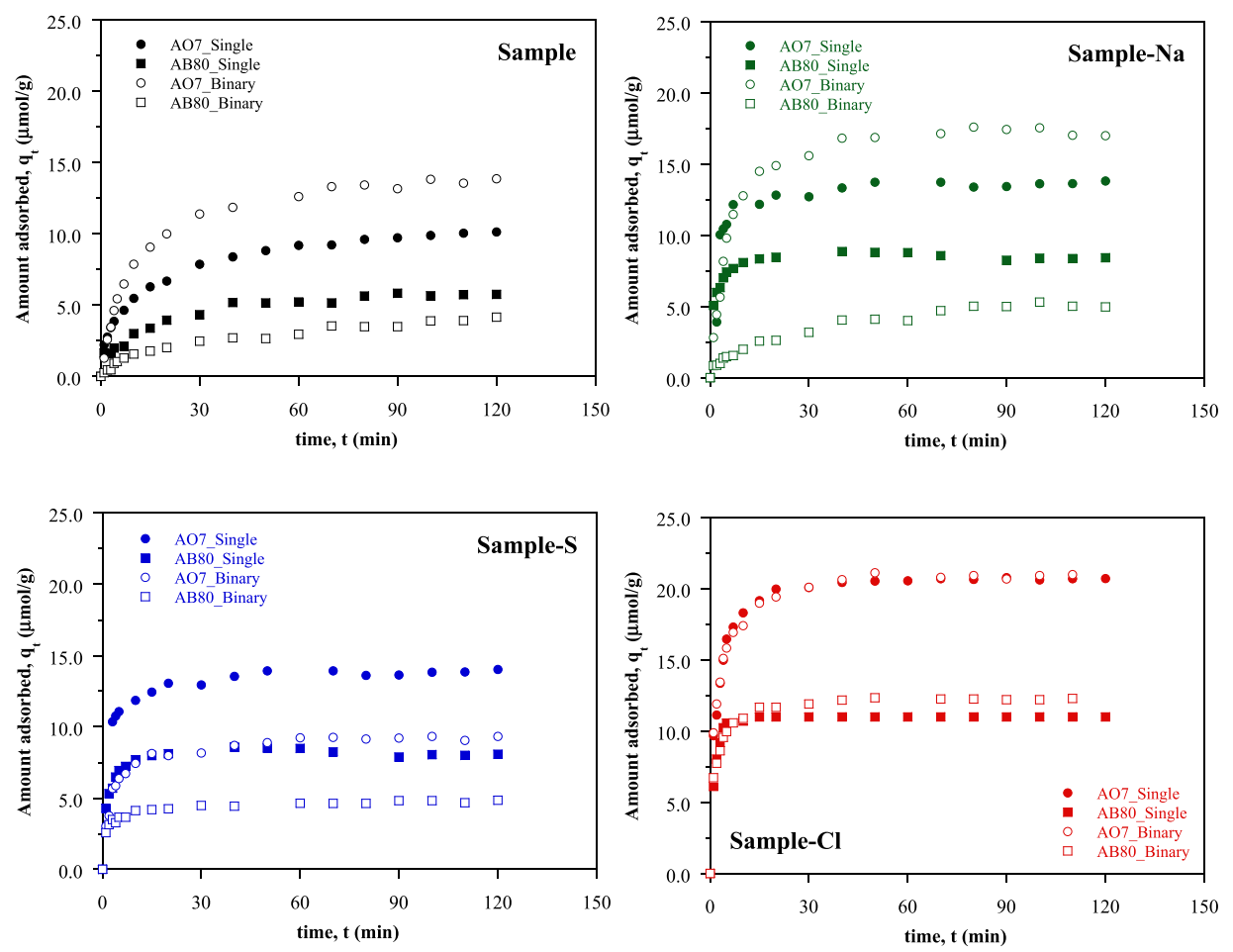

Figure 6. Kinetic adsorption data of $\mathrm{AB} 80$ and $\mathrm{AO} 7$ using samples as adsorbents for single and binary systems. 
Table 2. Effective Diffusion Coefficients for AB80 and AO7 Adsorption by the Samples Indicated ${ }^{a}$

\begin{tabular}{|c|c|c|c|c|}
\hline & sample & sample-Na & sample-S & sample-Cl \\
\hline \multicolumn{5}{|c|}{ AB80-Single } \\
\hline$D / r^{2}(1 / s)$ & $5.3 \times 10^{-5}$ & $57 \times 10^{-5}$ & $47 \times 10^{-5}$ & $69 \times 10^{-5}$ \\
\hline$\chi^{2}$ & 0.028 & 0.021 & 0.021 & 0.0030 \\
\hline$R$ & 0.992 & 0.990 & 0.991 & 0.998 \\
\hline \multicolumn{5}{|c|}{ AB80-Binary } \\
\hline$D / r^{2}(1 / s)$ & $2.7 \times 10^{-5}$ & $3.5 \times 10^{-5}$ & $33 \times 10^{-5}$ & $40 \times 10^{-5}$ \\
\hline$\chi^{2}$ & 0.057 & 0.050 & 0.076 & 0.018 \\
\hline$R$ & 0.98 & 0.98 & 0.96 & 0.992 \\
\hline \multicolumn{5}{|c|}{ AO7-Single } \\
\hline$D / r^{2}(1 / s)$ & $6.3 \times 10^{-5}$ & $29 \times 10^{-5}$ & $38 \times 10^{-5}$ & $31 \times 10^{-5}$ \\
\hline$\chi^{2}$ & 0.010 & 0.094 & 0.022 & 0.0084 \\
\hline$R$ & 0.997 & 0.96 & 0.98 & 0.997 \\
\hline \multicolumn{5}{|c|}{ AO7-Binary } \\
\hline$D / r^{2}(1 / s)$ & $5.8 \times 10^{-5}$ & $11 \times 10^{-5}$ & $19 \times 10^{-5}$ & $29 \times 10^{-5}$ \\
\hline$\chi^{2}$ & 0.022 & 0.036 & 0.032 & 0.020 \\
\hline$R$ & 0.995 & 0.990 & 0.98 & 0.991 \\
\hline
\end{tabular}

${ }^{a_{T}} \mathrm{~T}=25{ }^{\circ} \mathrm{C}, \mathrm{C}_{0}=15 \mathrm{mg} / \mathrm{dm}^{3}\left(0.022 \mathrm{mmol} / \mathrm{dm}^{3}\right.$ for $\mathrm{AB} 80$ and 0.022 $\mathrm{mmol} / \mathrm{dm}^{3}$ for $\left.\mathrm{AO} 7\right)$, and $\mathrm{pH}=2$.

affinity parameters of the adsorbents, $k_{\mathrm{L}}$, confirm the results obtained under kinetic conditions. From them, it was observed that AO7 had more affinity for the materials than AB80. In the case of the binary mixtures, the values of the coefficients change slightly.

2.3. $\mathrm{CO}_{2}$ Adsorption Experiments. The $\mathrm{CO}_{2}$ adsorption capacity of the samples at three temperatures and pressures up to $80 \mathrm{kPa}$ are shown in Figure 7. The adsorbed $\mathrm{CO}_{2}$ evolution with the temperature indicates that there is a physical interaction between the surface of the solids and $\mathrm{CO}_{2}$. The aluminum saline slag, sample, showed higher adsorption capacity than the wastes. At low pressures, sample and sample-Na show a similar and high capacity of adsorption, but at high pressures, the differences are more important. The adsorption at low pressures can be related to the interaction with specific sites of adsorption, estimated in this case by pHpzc and $\mathrm{V}\left(\mathrm{NH}_{3}\right)$, see Table 1 . The differences in textural properties can explain the results at high pressures. ${ }^{44}$ Sample shows a specific surface area of $84 \mathrm{~m}^{2} / \mathrm{g}$ and a micropore volume of $0.010 \mathrm{~cm}^{3} / \mathrm{g}$ in comparison to $42 \mathrm{~m}^{2} / \mathrm{g}$ and 0.002 $\mathrm{cm}^{3} / \mathrm{g}$ shown by sample-Na. In the case of the samples treated with acids, the low adsorption capacity of $\mathrm{CO}_{2}$ at low pressures with respect to the results observed for sample and sample- $\mathrm{Na}$ can be explained by the differences between pHpzc and $\mathrm{V}\left(\mathrm{NH}_{3}\right)$, from $2.0-3.7$ to $8.6-9.7$ for $\mathrm{pHpzc}$ and from 5.215.22 to $2.84-3.35 \mathrm{~cm}^{3} / \mathrm{g}$ for $\mathrm{V}\left(\mathrm{NH}_{3}\right)$. The low textural properties of the samples treated with acids also explain the results at high pressures. The experimental results indicate that the aluminum saline slags can be used as adsorbents to retain $\mathrm{CO}_{2}$ and that the chemical activation of these solids does not increase their adsorption capacity.

A comparison of the Henry's constants $(H)$, obtained from the isotherms in the low-pressure region (Table 3), showed that the constants were higher for sample and sample-Na than for sample-S and sample-Cl, and that the values decreased as the temperature increased. This behavior is related to a more important interaction of $\mathrm{CO}_{2}$ on the surface of the wastes at low temperatures and pressures. These results are also used to calculate the limiting heat, $q_{\mathrm{st}}^{0}$, by applying the ClausiusClapeyron equation in the low-pressure region. ${ }^{45}$ The isosteric heats obtained are included in Table 3, showing that the values
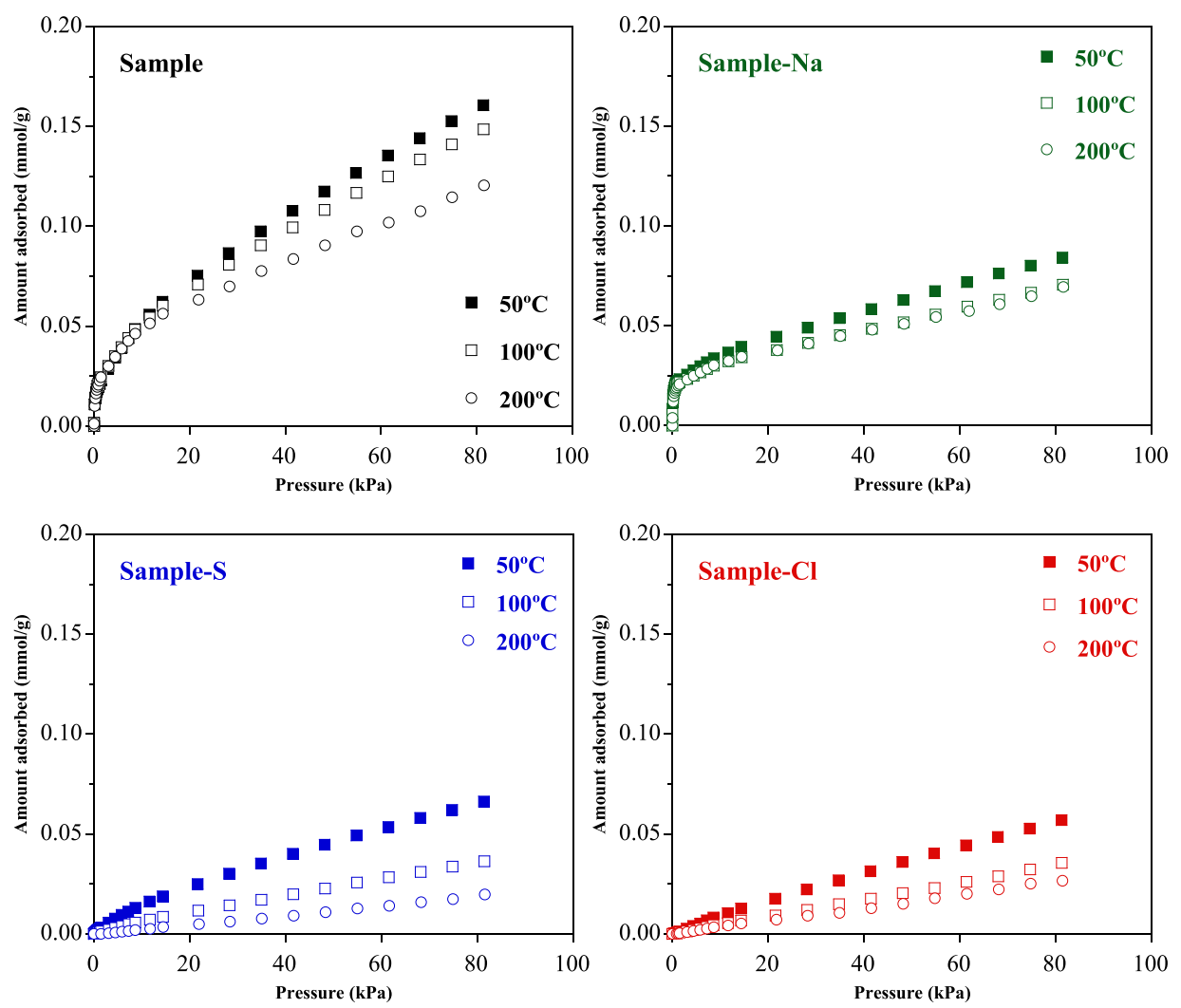

Figure 7. $\mathrm{CO}_{2}$ adsorption on the samples at 50,100 , and $200{ }^{\circ} \mathrm{C}$. 
Table 3. Henry's Constants for $\mathrm{CO}_{2}$ Adsorption at Several Temperatures and Isosteric Heats of Adsorption at Zero Coverage by the Samples Indicated

$\begin{array}{ccc}\text { samples/temperature }\left({ }^{\circ} \mathrm{C}\right) & \begin{array}{c}H(\mathrm{mmol} / \mathrm{kPa} \cdot \mathrm{g}) \\ \text { Sample }\end{array} & q_{\mathrm{st}}^{0}(\mathrm{~kJ} / \mathrm{mol})^{a} \\ 50 & 55.4 \times 10^{-3} & \\ 100 & 58.5 \times 10^{-3} & 1.7 \\ 200 & 52.8 \times 10^{-3} & \\ & \text { Sample-Na } & \\ 50 & 71.4 \times 10^{-3} & 1.7 \\ 100 & 65.7 \times 10^{-3} & \\ 200 & 58.6 \times 10^{-3} & \\ & \text { Sample-S } & \\ 50 & 3.0 \times 10^{-3} & \\ 100 & 0.75 \times 10^{-3} & \\ 200 & 0.13 \times 10^{-3} & \\ & \text { Sample-Cl } \\ 50 & 0.48 \times 10^{-3} & \\ 100 & 0.22 \times 10^{-3} & \\ 200 & 0.15 \times 10^{-3} & \\ { }^{a} \text { From the Henry constant. } & & \end{array}$

for sample and sample- $\mathrm{Na}$ were lower than for sample-S and sample- $\mathrm{Cl}$ in accordance with the adsorption capacity in this range of pressures.

The dependence of the isosteric heats of adsorption, calculated using the Clausius-Clapeyron equation, on the amount adsorbed for the samples is shown in Figure 8. The

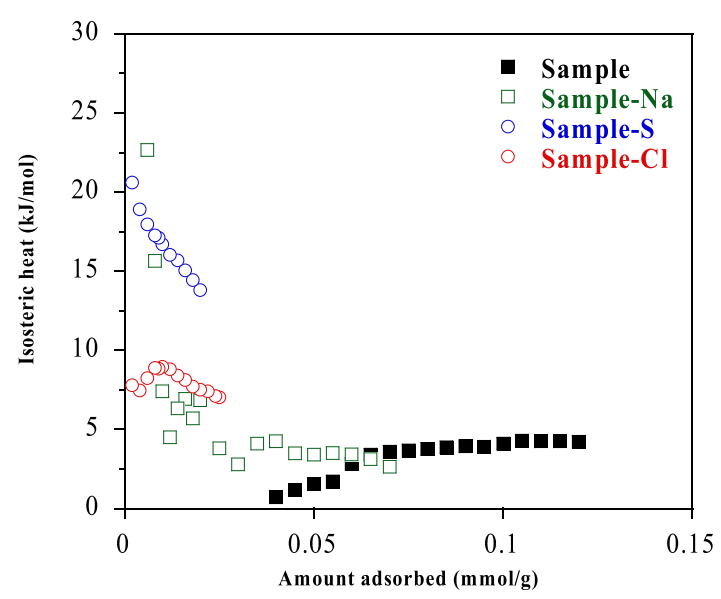

Figure 8. Isosteric heat of $\mathrm{CO}_{2}$ adsorption as a function of the amount of $\mathrm{CO}_{2}$ adsorbed on the samples.

results obtained show that for sample and sample-Cl, the isosteric heats are constant with loading, increasing at low loading in the case of sample-Na and sample-S. Schwaab et al. ${ }^{46}$ reported that the evolution of the isosteric heats with adsorbate loading can be related to the energetically homogeneous/ heterogeneous character of the adsorbents. In the case of sample and sample-Cl, the samples are energetically homogeneous toward $\mathrm{CO}_{2}$ adsorption. In the same way, sample and sample-S are energetically heterogeneous.

\section{SUMMARY AND CONCLUSIONS}

Herein, we have presented wastes produced, after the extraction of aluminum from saline slags generated during secondary aluminum recycling processes, as adsorbents for organic contaminants in contaminated liquid streams and $\mathrm{CO}_{2}$ removal. The materials were obtained by the treatment of saline slags with $2 \mathrm{~mol} / \mathrm{dm}^{3}$ aqueous solutions of $\mathrm{NaOH}$, $\mathrm{H}_{2} \mathrm{SO}_{4}$, and $\mathrm{HCl}$ under reflux conditions, which at the same time extracts a valuable amount of aluminum from the slag. The treatments modify the acidity-basicity properties of the solids. The resulting materials have been used as adsorbents for the removal of the acid dyes Acid Orange 7 and Acid Blue 80, considering single and binary component systems, and $\mathrm{CO}_{2}$ storage.

Taking into account the individual solutions, the preferential adsorption of $\mathrm{AB} 80$ compared to $\mathrm{AO} 7$ seems to be related to the number of sulfonic acid groups present in the dye molecules. The treatment of saline slag with aqueous solutions of $\mathrm{HCl}$ increases the acidic properties of the solids and their dye-adsorption capacity. In the case of treatment with aqueous $\mathrm{H}_{2} \mathrm{SO}_{4}$ solutions, the adsorption capacity of dyes is not favored by the presence of sulfate groups on the surface. A preferential adsorption of $\mathrm{AO} 7$ is observed compared to $\mathrm{AB} 80$ in binary solutions when using the starting material and the $\mathrm{NaOH}$ treated solid. No preferential adsorption is found in the case of the adsorbents obtained upon treatment with acids. Kinetic results allow to deduce that the adsorption of AO7 and $\mathrm{AB} 80$ on the aluminum saline slags takes place via a monolayer adsorption process. As a final conclusion, untreated starting materials or those treated with a base could be suitable for separating the components from the binary solutions.

The evolution of the amount of $\mathrm{CO}_{2}$ adsorbed with the temperature indicates that there is a physical interaction between the surface of the wastes and $\mathrm{CO}_{2}$. The adsorption on specific sites and the textural properties can explain the differences between the materials. The isosteric heats of $\mathrm{CO}_{2}$ adsorption from the Clausius-Clapeyron equation varied in the range of $1.7-26.8 \mathrm{~kJ} / \mathrm{mol}$.

\section{EXPERIMENTAL PROCEDURE}

4.1. Materials. Reagents used for the chemical activation of the aluminum saline slags were $\mathrm{NaOH}$ (Panreac), $\mathrm{H}_{2} \mathrm{SO}_{4}$ (98\%, Panreac), and $\mathrm{HCl}$ (37\%, Acros). Acid Blue 80 (Merck, 40\%) and Acid Orange 7 (Aldrich, 85\%) were selected as representative acid dyes. $\mathrm{NH}_{3}$ (Air Liquide, >99.995\%), $\mathrm{CO}_{2}$ (Praxair, 99.990\%), $\mathrm{N}_{2}$ (Praxair, 99.999\%), and $\mathrm{He}$ (Air Liquide, 99.998\%) were also used.

4.2. Adsorbents from Wastes. An aluminum saline slag previously treated with hot water was used as the material. The procedure and conditions for aluminum extraction with $\mathrm{NaOH}, \mathrm{H}_{2} \mathrm{SO}_{4}$, and $\mathrm{HCl}$ are reported in previous works. ${ }^{4,47}$ The results of aluminum extracted, determined by inductively coupled plasma atomic emission spectroscopy, are included in Figure S2 (Supporting Information), and the aluminum thus extracted was used for the synthesis of new materials. ${ }^{47}$ After the chemical reaction for aluminum extraction, the slurries were separated by filtration and washed several times with deionized water. The solids obtained, that is, the residual wastes, were dried at $60{ }^{\circ} \mathrm{C}$ for $16 \mathrm{~h}$ and considered as adsorbents of acid dyes and $\mathrm{CO}_{2}$. The nomenclature used for these solids is sample- $Y$, where $\mathrm{Y}$ is the reagent used in the chemical activation. Thus, for example, sample- $\mathrm{Na}$ is a solid treated with an aqueous solution of $2 \mathrm{~mol} / \mathrm{dm}^{3} \mathrm{NaOH}$ for $2 \mathrm{~h}$ under reflux conditions.

4.3. Characterization Techniques. $\mathrm{N}_{2}$ (Praxair, 99.999\%) adsorption-desorption measurements were obtained at $-196{ }^{\circ} \mathrm{C}$ from a Micromeritics ASAP 2010 
adsorption analyzer. The powder XRD patterns of the materials were carried out using a Siemens D-5000 diffractometer. SEM analysis of the samples was considered using a JEOL microscope, model JSM-6400.

pHpzc was determined from mass titrations by a procedure previously reported. ${ }^{41}$

The acidity of the samples was determined by adsorption of $\mathrm{NH}_{3}$ using a dynamic pulse method. The procedure and conditions are reported in a previous work. ${ }^{48}$

4.4. $\mathrm{CO}_{2}$ Adsorption Experiments. The procedure and conditions used for adsorption of $\mathrm{CO}_{2}$ at several temperatures are reported in a previous work. ${ }^{47}$

4.5. Dye Adsorption Procedure. Acid Blue 80 (AB80) and Acid Orange 7 (AO7) were selected as anionic dyes for this research. The properties of the dyes are summarized in Table S1 (Supporting Information). The concentration of the dye molecules in aqueous solutions was determined by an ultraviolet-visible spectrophotometer, Jasco V-730, at the maxima wavelength of absorption found, 485 and $627 \mathrm{~nm}$ for $\mathrm{AO} 7$ and $\mathrm{AB} 80$. The maximum absorbance was confirmed by scanning aqueous solutions of the dye over the spectral range of $290-800 \mathrm{~nm}$. As the absorbance peaks are well-separated in binary solutions, they can be used for concentration measurements. Calibration curves for both individual dyes and the binary system were carried out at a $\mathrm{pH}$ value of 2 ; this $\mathrm{pH}$ value was also used for the adsorption processes (see below).

The adsorption kinetics experiments were evaluated in the batch mode. Thus, three stock solutions of Acid Orange 7 (15 $\left.\mathrm{mg} / \mathrm{dm}^{3}, 0.022 \mathrm{mmol} / \mathrm{dm}^{3}\right)$, Acid Blue $80\left(15 \mathrm{mg} / \mathrm{dm}^{3}, 0.043\right.$ $\mathrm{mmol} / \mathrm{dm}^{3}$ ), and a binary system containing AO7 and AB80 (ratio of $1: 1$, totalizing $30 \mathrm{mg} / \mathrm{dm}^{3}$ ) were used. In a typical experiment, $0.2 \mathrm{~g}$ of the adsorbent was placed in contact with $100 \mathrm{~cm}^{3}$ of the dye solution at a $\mathrm{pH}$ value of 2 , and the mixture was stirred for predetermined intervals of time (between 0.5 and $120 \mathrm{~min}$ ). The solution was then separated from the adsorbent by filtration using Durapore membrane filters with a pore size of $0.45 \mu \mathrm{m}$. The amount of dye adsorbed on the waste $\left(q_{t}\right)$ was calculated by the equation

$$
q_{t, \mathrm{e}}=V \cdot\left(C_{0}-C_{t, \mathrm{e}}\right) / m
$$

where $C_{0}$ is the initial concentration $\left(\mu \mathrm{mol} / \mathrm{dm}^{3}\right), C_{t}$ is the concentration $\left(\mu \mathrm{mol} / \mathrm{dm}^{3}\right)$ at a certain adsorption time $t$ (min), $V$ is the solution volume $\left(\mathrm{dm}^{3}\right)$, and $m$ is the amount of sample added $(\mathrm{g})$.

The equilibrium adsorption capacity was determined from various initial concentrations of the dyes. The procedure and conditions are reported in a previous work. ${ }^{49}$ The amount of dye adsorbed on the material at equilibrium $\left(q_{\mathrm{e}}\right)$ was determined according to eq 1 , where $C_{\mathrm{e}}\left(\mu \mathrm{mol} / \mathrm{dm}^{3}\right)$ is the concentration of the dye at equilibrium. All experiments were carried out in duplicate.

4.4.1. Theoretical Approach: Adsorption Kinetics. The transport of adsorbate molecules inside porous adsorbents can be described by two types of kinetic modeling approaches. ${ }^{50}$ The first type of model considers simple relationships between the adsorption process and the operating conditions. These types of models describe how the average solid-phase concentration $(q)$ changes with the time of adsorption. Pseudo-first- and pseudo-second-order rate equations are included in this category. The second approach includes phenomenological models that attempt to describe the adsorption rate through the resistances of external mass transfer, intraparticle diffusion, and adsorption on the sites. Information on the adsorption mechanism can be obtained from the second type of models using the kinetic experimental results and the equilibrium adsorption data.

Considering mass balances to the liquid phase in the batch system and assuming first- and second-order kinetics for the driving force term, the following equations are obtained

$$
\begin{aligned}
& -\frac{\mathrm{d} n}{\mathrm{~d} t}=-V \frac{\mathrm{d} C}{\mathrm{~d} t}=k_{1} \cdot V \cdot\left(C-C_{\mathrm{e}}\right) \\
& -\frac{\mathrm{d} n}{\mathrm{~d} t}=-V \frac{\mathrm{d} C}{\mathrm{~d} t}=k_{2} \cdot \frac{V^{2}}{m} \cdot\left(C-C_{\mathrm{e}}\right)^{2}
\end{aligned}
$$

where $n(\mathrm{mmol})$ is the amount of organic molecule in the liquid phase, $V\left(\mathrm{~cm}^{3}\right)$ is the volume of the solution, $C(\mathrm{mmol} /$ $\left.\mathrm{dm}^{3}\right)$ is the organic molecule concentration in the solution, $m$ $(\mathrm{g})$ is the adsorbent mass, $t(\mathrm{~min})$ is the contact time, and $k_{1}$ $(1 / \mathrm{min})$ and $k_{2}(\mathrm{~g} / \mathrm{mmol} \cdot \mathrm{min})$ are the adsorption kinetic constants of the pseudo-first- and pseudo-second-order.

The equations can be integrated between the initial time and time $t$ and by considering the initial conditions (for $t=0, C=$ $C_{0}$ ). Under these situations, the following equations are obtained

$$
\begin{aligned}
& \ln \left(\frac{C_{t}-C_{\mathrm{e}}}{C_{0}-C_{\mathrm{e}}}\right)=-k_{1} \cdot t \\
& C_{t}=C_{\mathrm{e}}+\frac{V \cdot m \cdot\left(C_{0}-C_{\mathrm{e}}\right)}{m+k_{2} \cdot V \cdot\left(C_{0}-C_{\mathrm{e}}\right) \cdot t}
\end{aligned}
$$

The equations can also be expressed considering the relationship between the organic molecule concentration in the aqueous solution $(C)$ and in the solid phase $(q)$ as

$$
\begin{aligned}
& q_{t}=q_{\mathrm{e}} \cdot\left(1-\exp \left(-k_{1} \cdot t\right)\right) \\
& q_{t}=\frac{k_{2} \cdot q_{\mathrm{e}}^{2} \cdot t}{1+k_{2} \cdot q_{\mathrm{e}} \cdot t}
\end{aligned}
$$

These two equations have been employed to explain the adsorption of aqueous pollutants on adsorbents. ${ }^{4,51-56}$

The intraparticle diffusion model is applicable only within restrictive conditions. This model assumes that intraparticle diffusion is the rate-controlling step of the adsorption process. $^{57}$ This is the case when well-mixed solutions are considered. Under these situations, the intraparticle diffusivity is constant, and the uptake of the adsorbate by the material is small if the total quantity of the adsorbate present in the solution is taken into consideration. The equation for this model is

$$
q_{t}=k_{3} \cdot t^{0.5}
$$

where $k_{3}\left(\mathrm{mmol} / \mathrm{g} \cdot \mathrm{min}^{0.5}\right)$ is the intraparticle diffusion rate constant. This model has been previously applied to several adsorption systems. $9,51,54,58,59$

The effective diffusion coefficient can be calculated from the fractional approach to the equilibrium, $F(t)^{60}$

$$
F(t)=\frac{C_{0}-C_{t}}{C_{0}-C_{e}}=\left[1-\exp \left(-\frac{\pi^{2} \cdot D \cdot t}{r^{2}}\right)\right]^{0.5}
$$

where $D\left(\mathrm{~m}^{2} / \mathrm{s}\right)$ is the intraparticle diffusion coefficient and $r$ $(\mathrm{m})$ is the particle size radius assuming a spherical geometry. 
4.4.2. Theoretical Approach: Equilibrium. The adsorption equilibrium is often expressed by various isotherm equations. ${ }^{50}$ The Langmuir model considers monolayer coverage of adsorbent surfaces and can be represented for multicomponent studies as

$$
q_{\mathrm{e}, i}=\frac{k_{\mathrm{L}, i} \cdot q_{\mathrm{L}, i} \cdot C_{\mathrm{e}, i}}{1+\sum_{j=1}^{N} k_{\mathrm{L}, j} \cdot C_{\mathrm{e}, j}}
$$

where $k_{\mathrm{L}, i}\left(\mathrm{dm}^{3} / \mu \mathrm{mol}\right)$ and $q_{\mathrm{L}, i}(\mu \mathrm{mol} / \mathrm{g})$ are Langmuir constants that represent the equilibrium adsorption related to the affinity of binding sites and the monolayer adsorption capacity. This equation assumes that all adsorbates compete for energetically identical adsorption sites.

\section{ASSOCIATED CONTENT}

\section{S Supporting Information}

The Supporting Information is available free of charge on the ACS Publications website at DOI: 10.1021/acsomega.8b02397.

Characteristics of the dyes studied as adsorbates, kinetics parameters for dye adsorption, and aluminum extracted under several conditions (PDF)

\section{AUTHOR INFORMATION}

\section{Corresponding Author}

*E-mail: andoni@unavarra.es. Phone: +34 948169602 (A.G.). ORCID $\odot$

Antonio Gil: 0000-0001-9323-5981

Miguel Ángel Vicente: 0000-0002-6714-0249

Notes

The authors declare no competing financial interest.

\section{ACKNOWLEDGMENTS}

The authors are grateful for the financial support from the Seventh Framework Programme through the project RecycAl, the Spanish Ministry of Economy, Industry, and Competitiveness (AEI/MINECO), and the European Regional Development Fund (ERDF) through project MAT2016-78863-C2-R. A.G. also thanks Santander Bank for funding through the Research Intensification Program.

\section{REFERENCES}

(1) Reife, A.; Freeman, H. S. Environmental Chemistry of Dyes and Pigments; John Wiley \& Sons: New York, 1996.

(2) Eckenfelder, W. W., Jr. Wastewater Treatment. Kirk-Othmer: Chemical Technology and the Environment; John Wiley \& Sons: New York, 2007; pp 577-614.

(3) Yagub, M. T.; Sen, T. K.; Afroze, S.; Ang, H. M. Dye and its removal from aqueous solution by adsorption: A review. Adv. Colloid Interface Sci. 2014, 209, 172-184.

(4) Gil, A.; Albeniz, S.; Korili, S. A. Valorization of the saline slags generated during secondary aluminium melting processes as adsorbents for the removal of heavy metal ions from aqueous solutions. Chem. Eng. J. 2014, 251, 43-50.

(5) McKay, G.; Al-Duri, B. Extended empirical Freundlich isotherm for binary systems: a modified proce dure to obtain the correlative constants. Chem. Eng. Process. 1991, 29, 133-138.

(6) Choy, K. K. H.; Porter, J. F.; McKay, G. Langmuir Isotherm Models Applied to the Multicomponent Sorption of Acid Dyes from Effluent onto Activated Carbon. J. Chem. Eng. Data 2000, 45, 575584.
(7) Rio, S.; Delebarre, A.; Héquet, V.; Le Cloirec, P.; Blondin, J. Metallic ion removal from aqueous solutions by fly ashes: multicomponent studies. J. Chem. Technol. Biotechnol. 2002, 77, 382-388.

(8) Choy, K. K. H.; Porter, J. F.; McKay, G. Single and multicomponent equilibrium studies for the adsorption of acidic dyes on carbon from effluents. Langmuir 2004, 20, 9646-9656.

(9) Choy, K. K. H.; Porter, J. F.; Mckay, G. Intraparticle diffusion in single and multicomponent acid dye adsorption from wastewater onto carbon. Chem. Eng. J. 2004, 103, 133-145.

(10) Choy, K. K. H.; Allen, S. J.; Mckay, G. Multicomponent equilibrium studies for the adsorption of basic dyes from solution on lignite. Adsorption 2005, 11, 255-259.

(11) Chiou, M.-S.; Chuang, G.-S. Competitive adsorption of dye metanil yellow and RB15 in acid solutions on chemically cross-linked chitosan beads. Chemosphere 2006, 62, 731-740.

(12) Al-Degs, Y.; Khraisheh, M. A. M.; Allen, S. J.; Ahmad, M. N.; Walker, G. M. Competitive adsorption of reactive dyes from solution: equilibrium isotherm studies in single and multisolute systems. Chem. Eng. J. 2007, 128, 163-167.

(13) Turabik, M. Adsorption of basic dyes from single and binary component systems onto bentonite: simultaneous analysis of basic red 46 and basic yellow 28 by first order derivative spectrophotometric analysis method. J. Hazard. Mater. 2008, 158, 52-64.

(14) Noroozi, B.; Sorial, G. A.; Bahrami, H.; Arami, M. Adsorption of binary mixtures of cationic dyes. Dyes Pigm. 2008, 76, 784-791.

(15) Chan, L. S.; Cheung, W. H.; Allen, S. J.; McKay, G. Separation of acid-dyes mixture by bamboo derived active carbon. Sep. Purif. Technol. 2009, 67, 166-172.

(16) Pura, S.; Atun, G. Adsorptive Removal of Acid Blue 113 and Tartrazine by Fly Ash from Single and Binary Dye Solutions. Sep. Sci. Technol. 2009, 44, 75-101.

(17) Atun, G.; Acar, E. T. Competitive adsorption of basic dyes onto calcite in single and binary component systems. Sep. Sci. Technol. 2010, 45, 1471-1481.

(18) Mahmoodi, N. M.; Salehi, R.; Arami, M. Binary system dye removal from colored textile wastewater using activated carbon: kinetic and isotherm studies. Desalination 2011, 272, 187-195.

(19) Fernandez, M. E.; Bonelli, P. R.; Cukierman, A. L.; Lemcoff, N. $\mathrm{O}$. Modeling the biosorption of basic dyes from binary mixtures. Adsorption 2015, 21, 177-183.

(20) Duta, A.; Visa, M. Simultaneous removal of two industrial dyes by adsorption and photocatalysis on a fly-ash-TiO2 composite. $J$. Photochem. Photobiol., A 2015, 306, 21-30.

(21) Yu, J.-x.; Zhu, J.; Feng, L.-y.; Chi, R.-a. Simultaneous removal of cationic and anionic dyes by the mixed sorbent of magnetic and nonmagnetic modified sugarcane bagasse. J. Colloid Interface Sci. 2015, $451,153-160$.

(22) Mazaheri, H.; Ghaedi, M.; Asfaram, A.; Hajati, S. Performance of $\mathrm{CuS}$ nanoparticle loaded on activated carbon in the adsorption of methylene blue and bromophenol blue dyes in binary aqueous solutions: Using ultrasound power and optimization by central composite design. J. Mol. Liq. 2016, 219, 667-676.

(23) Yang, L.; Zhang, Y.; Liu, X.; Jiang, X.; Zhang, Z.; Zhang, T.; Zhang, $\mathrm{L}$. The investigation of synergistic and competitive interaction between dye Congo red and methyl blue on magnetic $\mathrm{MnFe} 2 \mathrm{O} 4$. Chem. Eng. J. 2014, 246, 88-96.

(24) Mahmoodi, N. M.; Hosseinabadi-Farahani, Z.; Chamani, H. Dye adsorption from single and binary systems using $\mathrm{NiO}$ $\mathrm{MnO} 2$ nanocomposite and artificial neural network modeling. AIChE J. 2016, 36, 111-119.

(25) Stawiński, W.; Węgrzyn, A.; Dańko, T.; Freitas, O.; Figueiredo, S.; Chmielarz, L. Acid-base treated vermiculite as high performance adsorbent: Insights into the mechanism of cationic dyes adsorption, regeneration, recyclability and stability studies. Chemosphere 2017, $173,107-115$

(26) Choi, S.; Drese, J. H.; Jones, C. W. Adsorbent materials for carbon dioxide capture from large anthropogenic point sources. ChemSusChem 2009, 2, 796-854. 
(27) Wang, J.; Huang, L.; Yang, R.; Zhang, Z.; Wu, J.; Gao, Y.; Wang, Q.; O'Hare, D.; Zhong, Z. Recent advances in solid sorbents for $\mathrm{CO} 2$ capture and new development trends. Energy Environ. Sci. 2014, 7, 3478-3518.

(28) Garcés, S. I.; Villarroel-Rocha, J.; Sapag, K.; Korili, S. A.; Gil, A. Comparative Study of the Adsorption Equilibrium of $\mathrm{CO} 2$ on Microporous Commercial Materials at Low Pressures. Ind. Eng. Chem. Res. 2013, 52, 6785-6793.

(29) Garcés-Polo, S. I.; Villarroel-Rocha, J.; Sapag, K.; Korili, S. A.; Gil, A. Adsorption of $\mathrm{CO} 2$ on mixed oxides derived from hydrotalcites at several temperatures and high pressures. Chem. Eng. J. 2018, 332, 24-32.

(30) D’Alessandro, D. M.; Smit, B.; Long, J. R. Carbon dioxide capture: prospects for new materials. Angew. Chem., Int. Ed. 2010, 49, $6058-6082$.

(31) Olivares-Marín, M.; Maroto-Valer, M. M. Development of adsorbents for $\mathrm{CO} 2$ capture from waste materials: a review. Greenhouse Gases: Sci. Technol. 2012, 2, 20-35.

(32) Ives, M.; Mundy, R. C.; Fennell, P. S.; Davidson, J. F.; Dennis, J. S.; Hayhurst, A. N. Comparison of Different Natural Sorbents for Removing CO2from Combustion Gases, as Studied in a Bench-Scale Fluidized Bed. Energy Fuels 2008, 22, 3852-3857.

(33) Li, Y.; Liu, C.; Sun, R.; Liu, H.; Wu, S.; Lu, C. Sequential SO2/ CO2 Capture of Calcium-Based Solid Waste from the Paper Industry in the Calcium Looping Process. Ind. Eng. Chem. Res. 2012, 51, $16042-16048$.

(34) Olivares-Marín, M.; Drage, T. C.; Maroto-Valer, M. M. Novel lithium-based sorbents from fly ashes for $\mathrm{CO} 2$ capture at high temperatures. Int. J. Greenhouse Gas Control 2010, 4, 623-629.

(35) Gil, A.; Arrieta, E.; Vicente, M. A.; Korili, S. A. Synthesis and $\mathrm{CO} 2$ adsorption properties of hydrotalcite-like compounds prepared from aluminum saline slag wastes. Chem. Eng. J. 2018, 334, 13411350.

(36) Ip, A. W. M.; Barford, J. P.; McKay, G. Reactive black dye adsorption/desorption onto different adsorbents: Effect of salt, surface chemistry, pore size and surface area. J. Colloid Interface Sci. 2009, 337, 32-38.

(37) Aznárez, A.; Gil, A.; Korili, S. A. Performance of palladium and platinum supported on alumina pillared clays in the catalytic combustion of propene. RSC Adv. 2015, 5, 82296-82309.

(38) Gil, A.; Santamaría, L.; Korili, S. A. Removal of caffeine and diclofenac from aqueous solution by adsorption on multiwalled carbon nanotubes. Colloid Interface Sci. Commun. 2018, 22, 25-28.

(39) Do, D. D. Adsorption Analysis: Equilibria and Kinetics; Imperial College Press: London, 1998.

(40) Gil, A.; Assis, F. C. C.; Albeniz, S.; Korili, S. A. Removal of dyes from wastewaters by adsorption on pillared clays. Chem. Eng. J. 2011, 168, 1032-1040.

(41) Hasan, Z.; Jeon, J.; Jhung, S. H. Adsorptive removal of naproxen and clofibric acid from water using metal-organic frameworks. J. Hazard. Mater. 2012, 209-210, 151-157.

(42) Kyzas, G. Z.; Kostoglou, M.; Lazaridis, N. K.; Lambropoulou, D. A.; Bikiaris, D. N. Environmental friendly technology for the removal of pharmaceutical contaminants from wastewaters using modified chitosan adsorbents. Chem. Eng. J. 2013, 222, 248-258.

(43) Álvarez-Torrellas, S.; Rodríguez, A.; Ovejero, G.; García, J. Comparative adsorption performance of ibuprofen and tetracycline from aqueous solution by carbonaceous materials. Chem. Eng. J. 2016, 283, 936-947.

(44) Essandoh, M.; Kunwar, B.; Pittman, C.U., Jr.; Mohan, D.; Mlsna, T. Sorptive removal of salicylic acid and ibuprofen from aqueous solutions using pine wood fast pyrolysis biochar. Chem. Eng. J. 2015, 265, 219-227.

(45) Gil, A.; Taoufik, N.; García, A. M.; Korili, S. A. Comparative removal of emerging contaminants from aqueous solution by adsorption on an activated carbon. Environ. Technol. 2018 (in press). DOI: $10.1080 / 09593330.2018 .1464066$
(46) Schwaab, M.; Steffani, E.; Barbosa-Coutinho, E.; Severo Júnior, J. B. Critical analysis of adsorption/diffusion modelling as a function of time square root. Chem. Eng. Sci. 2017, 173, 179-186.

(47) El Qada, E. N.; Allen, S. J.; Walker, G. M. Kinetic modeling of the adsorption of basic dyes onto steam-activated bituminous coal. Ind. Eng. Chem. Res. 2007, 46, 4764-4771.

(48) Sze, M. F. F.; McKay, G. An adsorption diffusion model for removal of para-chlorophenol by activated carbon derived from bituminous coal. Environ. Pollut. 2010, 158, 1669-1674.

(49) Khraisheh, M. A. M.; Al-Degs, Y. S.; Allen, S. J.; Ahmad, M. N. Elucidation of controlling steps of reactive dye adsorption on activated carbon. Ind. Eng. Chem. Res. 2002, 41, 1651-1657.

(50) Gregg, S. J.; Sing, K. S. W. Adsorption, Surface Area and Porosity; Academic Press: New York, 1991.

(51) Rouquerol, J.; Avnir, D.; Fairbridge, C. W.; Everett, D. H.; Haynes, J. M.; Pernicone, N.; Ramsay, J. D. F.; Sing, K. S. W.; Unger, K. K. Recommendations for the characterization of porous solids. Pure Appl. Chem. 1994, 66, 1739-1758.

(52) Gil, A.; Korili, S. A. Management and valorization of aluminum saline slags: Current status and future trends. Chem. Eng. J. 2016, 289, 74-84.

(53) Yoshimura, H. N.; Abreu, A. P.; Molisani, A. L.; de Camargo, A. C.; Portela, J. C. S.; Narita, N. E. Evaluation of aluminum dross waste as raw material for refractories. Ceram. Int. 2008, 34, 581-591.

(54) Huang, X.-L.; El Badawy, A. M.; Arambewela, M.; Adkins, R.; Tolaymat, T. Mineral phases and metals in baghouse dust from secondary aluminum production. Chemosphere 2015, 134, 25-30.

(55) Tsakiridis, P. E.; Oustadakis, P.; Moustakas, K.; Agatzini, S. L. Cyclones and fabric filters dusts from secondary aluminium flue gases: a characterization and leaching study. Int. J. Environ. Sci. Technol. 2016, 13, 1793-1802.

(56) Hamoud, H. I.; Finqueneisel, G.; Azambre, B. Removal of binary dyes mixtures with opposite and similar charges by adsorption, coagulation/flocculation and catalytic oxidation in the presence of $\mathrm{CeO}_{2} / \mathrm{H}_{2} \mathrm{O}_{2}$ Fenton-like system. J. Environ. Manage. 2017, 195, 195207.

(57) Duta, A.; Visa, M. Simultaneous removal of two industrial dyes by adsorption and photocatalysis on a fly-ash- $\mathrm{TiO}_{2}$ composite. $J$. Photochem. Photobiol., A 2015, 306, 21-30.

(58) Wang, K.; Qiao, S.; Hu, X. Study of isosteric heat of adsorption and activation energy for surface diffusion of gases on activated carbon using equilibrium and kinetics information. Sep. Purif. Technol. 2004, 34, 165-176.

(59) Sircar, S. Excess properties and thermodynamics of multicomponent gas adsorption. J. Chem. Soc., Faraday Trans. 1 1985, 81, $1527-1540$.

(60) Sircar, S.; Mohr, R.; Ristic, C.; Rao, M. B. Isosteric heat of adsorption: theory and experiment. J. Phys. Chem. B 1999, 103, $6539-6546$ 